\title{
Last-Mile Travel Mode Choice: Data-Mining Hybrid with Multiple Attribute Decision Making
}

\author{
Rui Zhao ${ }^{1}$, Linchuan Yang ${ }^{2, *} \mathbb{D}$, Xinrong Liang ${ }^{1}$, Yuanyuan Guo ${ }^{3}$, Yi Lu ${ }^{4} \mathbb{D}$, Yixuan Zhang ${ }^{1}$ \\ and Xinyun Ren ${ }^{1}$ \\ 1 Faculty of Geosciences and Environmental Engineering, Southwest Jiaotong University, Chengdu 611756, \\ China; ruizhaoswjtu@hotmail.com (R.Z.); XinrongLiang355@gmail.com (X.L.); \\ zhangyixuan1111@gmail.com (Y.Z.); rnxnyn@my.swjtu.edu.cn (X.R.) \\ 2 Department of Urban and Rural Planning, School of Architecture and Design, Southwest Jiaotong University, \\ Chengdu 611756, China \\ 3 Department of Geography and Resource Management, The Chinese University of Hong Kong, Hong Kong, \\ China; guoyuanyuan@link.cuhk.edu.hk \\ 4 Department of Architecture and Civil Engineering, City University of Hong Kong, Hong Kong, China; \\ yilu24@cityu.edu.hk \\ * Correspondence: yanglc0125@swjtu.edu.cn; Tel.: +86-028-6636-6683
}

Received: 12 November 2019; Accepted: 26 November 2019; Published: 27 November 2019

\begin{abstract}
Transit offers stop-to-stop services rather than door-to-door services. The trip from a transit hub to the final destination is often entitled as the "last-mile" trip. This study innovatively proposes a hybrid approach by combining the data mining technique and multiple attribute decision making to identify the optimal travel mode for last-mile, in which the data mining technique is applied in order to objectively determine the weights. Four last-mile travel modes, including walking, bike-sharing, community bus, and on-demand ride-sharing service, are ranked based upon three evaluation criteria: travel time, monetary cost, and environmental performance. The selection of last-mile trip modes in Chengdu, China, is taken as a typical case example, to demonstrate the application of the proposed approach. Results show that the optimal travel mode highly varies by the distance of the "last-mile" and that bike-sharing serves as the optimal travel mode if the last-mile distance is no more than $3 \mathrm{~km}$, whilst the community bus becomes the optimal mode if the distance equals 4 and $5 \mathrm{~km}$. It is expected that this study offers an evidence-based approach to help select the reasonable last-mile travel mode and provides insights into developing a sustainable urban transport system.
\end{abstract}

Keywords: last-mile; data mining; multiple attribute decision making; travel mode selection; big data; bike-sharing; community bus; on-demand ride-sharing service; Sina Weibo; China

\section{Introduction}

Cities worldwide have grappled with various conspicuous issues resulting from the excessive use of motor vehicles, including but not limited to traffic congestion, air/noise pollution, environmental degradation, limited green spaces, and carbon emissions. Against such a background, decreasing the motorized-trip frequency, uplifting the proportion of nonmotorized trips (e.g., walking and cycling), and lowering motorized-trip distances have been deemed as critical transportation objectives [1]. To establish an accessible, attractive, and environmentally friendly transport system that fulfills mobility needs, preferences, and demands of city residents is deemed as an effective means to mitigate transportation-related "urban diseases" [1,2].

As typical low-carbon, resource-saving, and sustainable travel modes, walking and cycling demand appropriate physical activities of human beings and mitigate sedentary lifestyles [3,4]. As such, they 
have gained immense popularity and interest globally [5,6]. For example, in 2012, the Ministry of Transport, the Ministry of Finance, and the National Development and Reform Commission of China jointly released the Guidance on Strengthening the Development of Walking and Cycling Systems. However, walking and cycling themselves cannot be solely used to meet medium/long-distance travel demands, but they can serve as feeder modes of transit modes, including but not limited to the subway, bus, ferry, and tram $[2,7]$.

As an imperative, economically feasible, low-carbon, and environmentally friendly travel mode, transit is often perceived to have the potential to relieve various conspicuous transportation-related "urban diseases" and has thus gained increasing popularity and attracted substantial attention from, inter alia, policy makers and academics [8]. Generally, transit offers stop-to-stop services rather than door-to-door services. As such, in most cases, the trip of a transit rider from a transit stop (or station, hub) to his/her final destination, which is often known as the "last-mile" trip, is indispensable.

Multiple travel modes, including walking, (station-based or dockless) bike-sharing, community bus (or feeder bus), and (on-demand) ride-sharing service (RSS, such as Uber and Lyft in the United States and Didi Chuxing in China), can be used to handle last-mile trips. It is clear that they have their advantages and drawbacks. For example, walking is easily incorporated into a daily routine and has a wide array of environmental (e.g., reducing car-related energy consumption, fuel use, and carbon dioxide emissions), economic (e.g., decreasing fuel cost and travel fare), health (e.g., lowering the risk of depression and obesity), and social benefits (e.g., increasing social capital, encouraging social interaction, and strengthening weak social ties) $[9,10]$. It, however, may only be applicable in short trips, because of physical or mobility limitations. As Munoz-Raskin [11] proposed, pedestrians can only bear walking no more than $10 \mathrm{~min}$ to access transit. In a similar vein, dockless bike-sharing, which is prevailing in many contexts (e.g., China and Singapore), has numerous advantages, such as flexibility and ease to pick up and drop off $[12,13]$. However, riders may park it arbitrarily, and such disorderly parking behaviors may give rise to traffic congestion and other congestion-induced issues, such as lost productive time [12]. Likewise, the RSS is featured as personalized, door-to-door and demand-responsive (or on-demand) service, wide spatial/temporal coverage, flexibility, and time-saving. Its fare, however, is fairly high, laying out an issue related to affordability.

The selection of travel modes can be deemed as a multiple attribute decision making (MADM) problem due to trade-offs among various conflicting criteria. Its associated weighting methods include, but are not limited to, simple additive weighting method, weighted product method, Delphi method, analytic hierarchy process (AHP) method, and multiplicative AHP method, and entropy method. However, they have their own characteristics, advantages, and shortcomings. In other words, all of them are far from perfect and still subject to criticisms and challenges. For example, the AHP method is a simple-to-operate but time-consuming criterion-weight-determination method, allowing hierarchical modeling of the problem. Put it in another way, AHP intends to decompose a complex decision issue into a set of hierarchies, through which an ordered decision is produced based upon pairwise comparison [14]. It was initially developed by Saaty in the 1970s [15]. Since then, the AHP method has received thriving scholarly attention, and also quite a few criticisms (e.g., rank reversal) and has thus been extensively refined by numerous researchers [16] and evolved into weighting assignment for a number of criteria in a hierarchical indicator system [17]. However, it highly hinges on, and thus is easily distorted by, the knowledge or experience of resorted individual experts, though it has been substantially improved; and it is time-consuming in computation, especially when the number of alternatives or attributes is large in the decision-making process [18].

To fill the above gap, this study proposes an approach by combining the data mining technique with MADM to help optimally select travel modes for last-mile. More specifically, four last-mile modes, including walking, bike-sharing, community bus (shortened to "bus" hereinafter), and RSS, serve as decision-making units and constitute the choice set; three indicators, travel time, monetary cost, and environmental performance, are set as evaluation criteria; and Sina Weibo data are used to determine the weights of the proposed criteria (data mining). A case example in Chengdu, China, is 
provided to empirically identify the optimal travel mode for different last-mile distances (ranging from 1 to $5 \mathrm{~km}$ ). Our findings are expected to improve the efficiency of the transit service and provide insights into policy making on last-mile transportation planning and management. Methodologically, this study clearly shows that the combination of the two techniques (i.e., data mining and MADM) creates new possibilities for investigating many important existing and new issues. The main contributions of this paper include the following: (1) innovatively proposing a data-mining-based weight determination method for MADM; (2) using data mining and MADM for a comprehensive analysis of the last-mile travel-mode-selection problem; and (3) giving new insights into the last-mile travel-mode selection.

The remainder of this paper is organized as follows. Section 2 provides a comprehensive and systematic review of existing literature on mode selection, not necessarily for last-mile trips. Section 3 proposes the hybrid method of data mining technique and MADM. Section 4 discusses the research findings. Section 5 concludes the paper and points out research limitations and future avenues.

\section{Literature Review}

Travel time and travel (monetary) cost have been recognized as the most important factors in travel-mode choice or selection in a voluminous body of existing literature [19], predominantly because the two level-of-service variables serve as the strongest and the most negatively perceived disincentives. To date, numerous studies have devoted to teasing out the effects of travel time and travel cost on mode choice in various contexts, particularly in the United States and Europe. Ortúzar [20] determined that travel time and travel cost are significant variables in shaping mode choice in Leeds, the United Kingdom, by adopting multinomial logit and nested logit models. Stern [21] investigated the travel-mode choice of the elderly and the disabled in rural Virginia, the United States, and addressed that a generalized travel cost significantly affects the choice. Schmöcker et al. [22] confirmed that travel time and travel cost significantly affect mode choice of the elderly and the disabled in London, the United Kingdom, for shopping trips by employing nested logit models. On the other hand, there has been another strand of research devoted to determining the optimal travel mode based on travel time and/or travel cost. By using revealed-preference data gathered from a trip survey, Wang et al. [23] proposed an optimization model (with an objective function of minimizing the generalized travel cost) to determine the optimal city-wide travel mode share of Beijing, China. Similarly, Salonen et al. [19] determined the optimal mode choice for trips in Helsinki, Finland, solely based on travel time. In other words, the authors used the fastest travel mode as the optimal choice.

In addition to travel time and travel cost, other factors (e.g., traveler's socioeconomic and demographic variables, neighborhood-level built environment variables, attitude or perception variables, and trip-related variables) have widely been taken into account in a number of travel-mode choice-studies. Schwanen et al. [24] believed that the modal choice of senior citizens for leisure trips is affected by travelers' socioeconomic and demographic variables, such as age, gender, and car availability. $\mathrm{Su}$ et al. [25] ascertained that contributory factors of travel-mode choice of the elderly in London include travel cost, age, gender, car availability, and transportation accessibility. Tilahun et al. [26] investigated the travel-mode choice in Chicago by using a multinomial logit model, and the factors concerned included parking costs, transit availability, and community crime. Moniruzzaman and Páez [27] confirmed that travel mode choice in Hamilton, Canada, is influenced by transit accessibility (to-transit and by-transit accessibility) and built environment variables. Jenelius et al. [28] deliberately divided travel time into waiting time, transfer time, and in-vehicle time in choosing the optimal bus line in Stockholm, from the perspective of service reliability. Yang et al. [29] established a discrete choice model to explore the factors influencing the travel-mode choice of residents in Beijing and demonstrated that attitudes about comfort and waiting time are correlated with the mode choice. Koopmans et al. [30] analyzed travel-mode choice in the Netherlands and found that trip purpose, trip distance, and rush hour affect the choice.

Traditionally, the identification of the optimal travel mode is mainly based on travel time and/or travel cost [19]. This, however, is inadequate in the era of the increasing awareness of climate change 
and carbon emissions [31]. In other words, carbon emissions reduction should be regarded as an additional criterion for determining the optimal travel mode. Existing literature provides strong evidence supporting the implication that the travel mode shift has the potential to contribute to the reduction of carbon emissions. He et al. [32] confirmed that $21 \%$ of energy-related emissions in China's transportation sector can be decreased by encouraging transit and limiting private cars. Cao et al. [33] developed a structural equation model to examine the impact of commuting trips on carbon emissions reduction, and their results clearly revealed the necessity of green transportation. Neves et al. [34] conducted interviews for local residents in Cardiff and Wales, and the corresponding results indicated that the residents prefer walking and cycling to the car, for short trips, due to their contributions to the reduction of carbon emissions. Yang et al. [29] confirmed that a transit improvement plan decreases carbon emissions by $12.3 \%-16.6 \%$ (for commuting and to-school trips) and $2.9 \%-6.8 \%$ (for other trips).

To sum up, existing literature mainly focuses on travel-mode choice for general trips or a specific trip type (e.g., commuting trips and shopping trips). More specifically, contributory factors of travel-mode choice and the identification of optimal travel modes have extensively been studied. However, the travel-mode choice for last-mile trips has not attracted much scholarly attention to date. In addition, most of the related studies used questionnaire surveys and interviews for data collection. However, these data-collection methods have a series of inherent drawbacks, such as high monetary cost, small sample size, and recall bias; in addition, the validity of research can be questioned and challenged [35]. To fill in the above gaps, this study considers composite criteria, namely, travel time, travel cost, and carbon emissions, for last-mile travel-mode decision making. Notably, it uses a big data approach to obtain the weights of criteria. Put it in another way, methodologically, this study proposes an approach that combines data mining and MADM to identify the optimal mode in last-mile travel. A data mining approach is employed to obtain the weights corresponding to the proposed criteria. It is expected that this study offers an evidence-based approach to guiding residents to choose the reasonable last-mile travel mode and provides insights into developing a sustainable urban transport system.

\section{Methodology and Data}

\subsection{Indicator System for the Last-Mile Travel-Mode Selection}

In this study, last-mile travel modes considered for the selection include walking, bike-sharing, bus, and RSS, and three sets of evaluation criteria, i.e., travel time, monetary cost, and environmental performance, are taken into evaluation. The indicator system for last-mile travel-mode selection is shown in Figure 1.

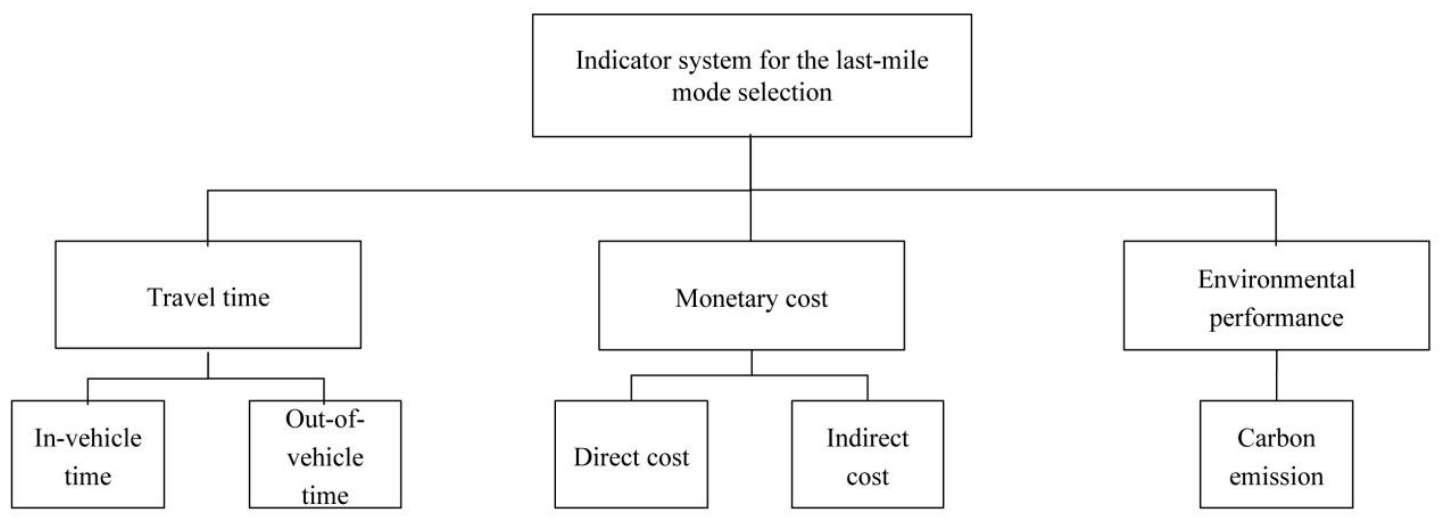

Figure 1. Indicator system for last-mile travel-mode selection. 


\subsubsection{Travel Time}

The travel time of walking for last-mile $\left(T_{w}\right)$ is measured as follows:

$$
T_{w}=\frac{s}{v_{w}}
$$

where $s$ is the travel distance $(\mathrm{km})$, and $v_{w}$ is the average walking speed $(\mathrm{km} / \mathrm{min})$.

Different from walking, the travel time of bike-sharing, the bus, and the RSS include in-vehicle time and out-of-vehicle time. The travel time of bike-sharing for last-mile $\left(T_{b}\right)$ is measured as follows:

$$
T_{b}=t_{b o}+\frac{s}{v_{b}}
$$

where $t_{b o}$ is the bike-searching time (or out-of-bike time) ( $\left.\mathrm{min}\right) ; v_{b}$ is the average cycling speed $(\mathrm{km} / \mathrm{min}$ ); and $s$ is as defined before.

The travel time of the bus for last-mile $\left(T_{c}\right)$ is measured as follows:

$$
T_{c}=t_{c o}+\frac{s}{v_{c}}
$$

where $t_{c o}$ is the wait time (or out-of-vehicle time) $\mathrm{min} ; v_{c}$ is the average bus travel speed $(\mathrm{km} / \mathrm{min}$ ); and $s$ is as defined before.

The travel time of the RSS for last-mile $\left(T_{r}\right)$ is measured as follows:

$$
T_{r}=t_{r o}+\frac{s}{v_{r}}
$$

where $t_{r o}$ is the wait time (or out-of-vehicle time) ( $\left.\mathrm{min}\right) ; v_{r}$ is the average RSS travel speed $(\mathrm{km} / \mathrm{min}$ ); and $s$ is as defined before.

\subsubsection{Monetary Cost}

The monetary cost includes direct cost and indirect cost. The former indicates the per-trip cost, such as travel fare, while the latter refers to the one-off cost, such as bus-card purchase cost and bike-sharing deposit.

The monetary cost of walking is set as 0 .

The monetary cost of bike-sharing $\left(M_{b}\right)$ is expressed as follows:

$$
M_{b}=\left\{\begin{array}{c}
m_{b} \text { if } \frac{s}{v_{b}} \leq t \\
m_{b}+m_{c} \text { if } \frac{s}{v_{b}}>t
\end{array}\right.
$$

where $m_{b}$ is the initial charge (or basic fee); $t$ is the maximum use time (e.g., $1 \mathrm{~h}$ ) with the initial charge (e.g., 1 Yuan); $m_{c}$ is the additional charge (Yuan) if the riding time exceeds $t$; and $s$ is as defined before.

The monetary cost of the bus $\left(M_{\mathcal{C}}\right)$, which assumes to adopt a flat (or uniform) fare structure in this study, is expressed as follows:

$$
M_{c}=\frac{a}{r_{z}}+b
$$

where $a$ is the bus card capital cost (or purchasing cost) (Yuan); $r_{z}$ is the average use time of a bus card throughout its life; and $b$ is the flat (or constant) travel price (Yuan).

The RSS normally adopts a nonlinear fare structure, which assumes to correlate with both travel distance and travel time in this study. If travel distance and travel time are smaller than prespecified threshold values, only the initial charge (e.g., 9 Yuan in Chengdu) needs to be paid. Otherwise, additional charges need to be paid. As such, the monetary cost of the RSS $\left(M_{t}\right)$ is expressed as follows:

$$
M_{r}=\max \left(U, s \times m_{d}+\frac{s}{v_{r}} \times m_{t}\right)
$$


where $m_{d}$ is the cost per kilometer (Yuan/km); $m_{t}$ is the cost per min (Yuan/min); $U$ is the initial charge (Yuan); and other variables are as defined before.

\subsubsection{Environmental Performance}

The environmental performance of last-mile travel is measured by direct greenhouse gas emissions, equivalent to a total amount of carbon dioxide in terms of their global-warming potentials. Walking and bike-sharing are not directly related to fossil fuel combustion, and, therefore, their direct carbon emissions are set to be 0 in this study.

The carbon emissions of bus travel $\left(E_{c}\right)$ can be expressed as follows:

$$
E_{c}=\frac{c_{\mathcal{c}} \times e_{\mathcal{c}} \times s}{q}
$$

where $c_{c}$ is the carbon emissions factor $(\mathrm{kg} / \mathrm{GJ})$ for the bus fuel; $e_{c}$ is the average fuel consumption (GJ) per kilometer of bus travel; $q$ is the average passenger volume of the bus; and $s$ is as defined before.

The carbon emissions of RSS travel $\left(E_{r}\right)$ can be expressed as follows:

$$
E_{r}=\frac{c_{r} \times e_{r} \times s}{p}
$$

where $c_{r}$ is the carbon-emissions factor $(\mathrm{kg} / \mathrm{GJ})$ for the RSS fuel; $e_{r}$ is the average fuel consumption (GJ) per kilometer of RSS travel; $p$ is the average passenger volume of the RSS; and $s$ is as defined before.

\subsection{Data-Mining-Based Weighting Method}

This study uses a data-mining-based weight determination method and MADM to rank the four last-mile modes (Figure 1). Generally, weight determination methods can be roughly categorized into two groups, subjective method (e.g., AHP method and multiplicative AHP method) and objective method (e.g., simple additive weighting method, weighted product method, entropy method, neural network method, standard deviation method, and data envelopment analysis) [36]. Both categories of the methods, however, have their own specific shortcomings. In this study, weights of all criteria were obtained by the keyword frequency, which likely guarantees their objectivity.

In this study, data mining used the "Weibo search" function of Sina Weibo, and the four trip modes were set as keywords. Sina Weibo is a popular online social network platform in China (like Twitter in the United States), through which users can release microblogs (weibos) and disseminate, share, and obtain information. It accounts for a high proportion of users of Weibo in China, and its users cover a broad spectrum of Chinese people. This feature provides detailed sample data support for this study.

The data used for the subsequent analysis stretched from 1 January 2017 to 31 December 2017. Through the use of the Octopus network data collector, data crawling rules were written in the custom mode, and Weibo data were automatically obtained and saved. A total of 54,429 Weibo observations were finally obtained by using specified keywords for search, and the BlueMC platform was used to analyze the word frequency. Keywords with the first 1000 frequency were selected, and the keywords related to each indicator were fetched. The word frequency was used as the index weight, which can be expressed as $\mathrm{W}=\left[\begin{array}{lll}\mathrm{w}_{1}, & \mathrm{w}_{2}, \mathrm{w}_{3}\end{array}\right]$.

Because the selected criteria may have different dimensions, it is necessary to normalize the data to a common scale for comparison. The attribute matrix (A) for each travel distance $(1,2,3,4$, and $5 \mathrm{~km}$ in this study) is constructed as follows:

$$
\mathrm{A}=\left(a_{i j}\right)_{n \times 3}
$$

where $i$ represents the travel-mode index, and $i=1,2,3,4,5, \ldots$, n represents walking, bike-sharing, the bus, the RSS, and various possible travel-mode combinations (e.g., walking + bus), respectively; $j=1,2,3$ indicates travel time, monetary cost, environmental performance of travel mode $i$, respectively; and $a_{i j}$ is the value of criteria $j$ of travel mode $i$ (see Equations (1) to (9)). 
The transformation rule used to convert indicator $a_{i j}$ to standardized indicator $\widetilde{a_{i j}}$ was as follows:

$$
\widetilde{a_{i j}}=\frac{a_{i j}-\mu_{j}}{s_{j}}
$$

where $\mu_{j}$ and $s_{j}$ represent the mean and the standard deviation of criteria $j$, respectively. Mathematically, $\mu_{j}$ and $s_{j}$ can be expressed as follows:

$$
\begin{gathered}
\mu_{j}=\frac{1}{n} \sum_{i=1}^{n} a_{i j} \\
s_{j}=\sqrt{\frac{1}{n-1} \sum_{i=1}^{n}\left(a_{i j}-\mu_{j}\right)^{2}}
\end{gathered}
$$

After standardization, the normalized attribute matrix becomes $\left(\widetilde{a_{i j}}\right)_{n \times 3}$.

\subsection{Data and Preliminary Results}

The study area is Chengdu, a sub-provincial, inland city located in the southwest part of China and the western part of the Sichuan Basin. It is the capital and the educational, financial, cultural, business, trade, technology, and transportation center of Sichuan Province and an economic hub of Western China. As of the end of 2017, Chengdu has a total population of 14.35 million, and it covers a land area of roughly 14.34 thousand $\mathrm{km}^{2}$, consisting of eleven districts, five county-level cities, and four counties.

In recent years, the Chengdu government has taken a series of transportation policy measures aiming at effectively meeting diversified travel demands and improving the quality of last-mile travel services. Under this background, the role of last-mile travel services in the transport system has considerably emphasized and strengthened, and the services have gradually been improved.

By investigating last-mile travel modes of Chengdu residents, this study comprehensively evaluates and ranks four travel modes and various travel-mode combinations in different travel distances to verify the effectiveness of the proposed data-mining-based weighting and MADM coupling method.

The weights of the three criteria were derived by counting their corresponding keywords (Table 1). Table 1 presents the results of the data-mining-based weighting. Keywords within the category of travel time received the greatest attention from Sina Weibo users (frequency $=11,757$ ), followed by those within monetary cost (frequency $=7046$ ). The weight of travel time, monetary cost, and environmental performance are $0.49,0.29$, and 0.22 , respectively.

Table 1. Results of data-mining-based weighting.

\begin{tabular}{cccccc}
\hline Travel time & \multicolumn{2}{c}{ Monetary cost } & \multicolumn{2}{c}{ Environmental Performance } \\
\hline Keyword & Frequency & Keyword & Frequency & Keyword & Frequency \\
\hline $\begin{array}{c}\text { Convenience (fangbian, } \\
\text { bianli, bianmin, or bianjie) }\end{array}$ & 8175 & Deposit (yajin) & 3228 & Green (lvse) & 374 \\
\hline $\begin{array}{c}\text { Rapid (kuaisu, gaosu, or } \\
\text { kuai) }\end{array}$ & 2294 & $\begin{array}{c}\text { Economy } \\
\text { (jingji) }\end{array}$ & 1688 & $\begin{array}{c}\text { Alternative energy (xin } \\
\text { nengyuan) }\end{array}$ & 584 \\
\hline Speed (sudu) & 315 & Free (mianfei) & 907 & Energy-saving (jieneng) & 347 \\
\hline Slow (man) & 228 & Hire (zulin) & 593 & Pollution (wuran) & 289 \\
\hline Inconvenience (bubian) & 477 & Charge (shoufei) & 352 & & \\
\hline Efficiency (xiaolv) & 268 & 1 Yuan (yiyuan) & 278 & & \\
\hline Sum & 11,757 & 7046 & & & \\
\hline Proportion & 0.49 & 0.29 & & \\
\hline
\end{tabular}


Parameter values in Equations (1) to (9) were obtained through field investigations, field experiments, governmental documents, research reports, etc. Their details are shown in Table 2.

Table 2. Values used in this study.

\begin{tabular}{|c|c|c|c|}
\hline Travel Mode & Parameter & Value & Source \\
\hline Walking & $v_{w}$ & $0.073 \mathrm{~km} / \mathrm{min}$ & $\begin{array}{l}\text { Road Capacity Manual (daolu tongxing nengli } \\
\text { shouce) }\end{array}$ \\
\hline \multirow{4}{*}{ Bike-sharing } & $t_{b o}$ & $2.38 \mathrm{~min}$ & Field experiment \\
\hline & $v_{b}$ & $\begin{array}{c}0.1895 \\
\mathrm{~km} / \mathrm{min}\end{array}$ & Field experiment \\
\hline & $t$ & $\geq 30 \mathrm{~min}$ & Field investigation \\
\hline & $m_{b}$ & 1 Yuan & Field investigation \\
\hline \multirow{8}{*}{ Bus } & $t_{c o}$ & $4.97 \mathrm{~min}$ & Field investigation \\
\hline & $v_{c}$ & $0.333 \mathrm{~km} / \mathrm{min}$ & $\begin{array}{l}\text { Implementation Opinions of the Priority Development } \\
\text { of Urban Transit in the Chengdu Government } \\
\text { (chengdushi renmin zhengfu guanyu youxian fazhan } \\
\text { chengshi gonggong jiaotong de shishi yijian) }\end{array}$ \\
\hline & $a$ & 20 Yuan & Field investigation \\
\hline & $r_{z}$ & $\gg 20$ & Field investigation \\
\hline & $b$ & 0 Yuan & Field investigation \\
\hline & $c_{c}$ & $15.3 \mathrm{~kg} / \mathrm{GJ}$ & $\begin{array}{l}\text { Provincial Guidelines for Greenhouse Gas Inventories } \\
\text { (shengji wenshi qiti qingdan bianzhi zhinan) }\end{array}$ \\
\hline & $e_{c}$ & $10.91 \mathrm{MJ} / \mathrm{km}$ & $\begin{array}{l}\text { Patterns and Load of Gas Emissions by the CNG } \\
\text { Automobile in Chengdu (chengdushi CNG qiche } \\
\text { yongqi guilv ji yongqi fuhe) }\end{array}$ \\
\hline & $q$ & 22.95 & $\begin{array}{c}\text { Calculated based on Chengdu Transportation } \\
\text { Development Annual Report } 2016\end{array}$ \\
\hline \multirow{8}{*}{ RSS } & $t_{r o}$ & $5.6 \mathrm{~min}$ & Didi Smart Travel Big Data Report \\
\hline & $m_{d}$ & 1.6 Yuan $/ \mathrm{km}$ & Field investigation \\
\hline & $v_{r}$ & $0.593 \mathrm{~km} / \mathrm{min}$ & Didi 2017 Urban Traffic Travel Report \\
\hline & $m_{t}$ & 0.3 Yuan/min & Field investigation \\
\hline & $U$ & 9 Yuan & Field investigation \\
\hline & $c_{r}$ & $18.9 \mathrm{~kg} / \mathrm{GJ}$ & Guidelines for Provincial Greenhouse Gas Inventories \\
\hline & $e_{r}$ & $0.180 \mathrm{GJ} / \mathrm{km}$ & Field investigation \\
\hline & $p$ & 2 passengers & Field investigation \\
\hline
\end{tabular}

\section{Results and Discussion}

\subsection{Results of Mode Selection for Last-Mile Trips in Five Scenarios}

Five scenarios with a last-mile travel distance of 1,2,3,4, or $5 \mathrm{~km}$ were considered, and four travel modes and a variety of their combinations were ranked according to the proposed method. Figure 2 shows the results of two scenarios (travel distance $=1$ or $2 \mathrm{~km}$ ). In the two scenarios, bike-sharing is ranked first. On the one hand, it has a significant speed advantage over walking, 2.6 times over that of walking. On the other hand, the out-of-vehicle time is substantially shorter than that of the bus and the RSS. Moreover, it has an unrivaled advantage in the domain of carbon emissions compared with the bus and the RSS during the use process. 
(a) Distance $=1 \mathrm{~km}$

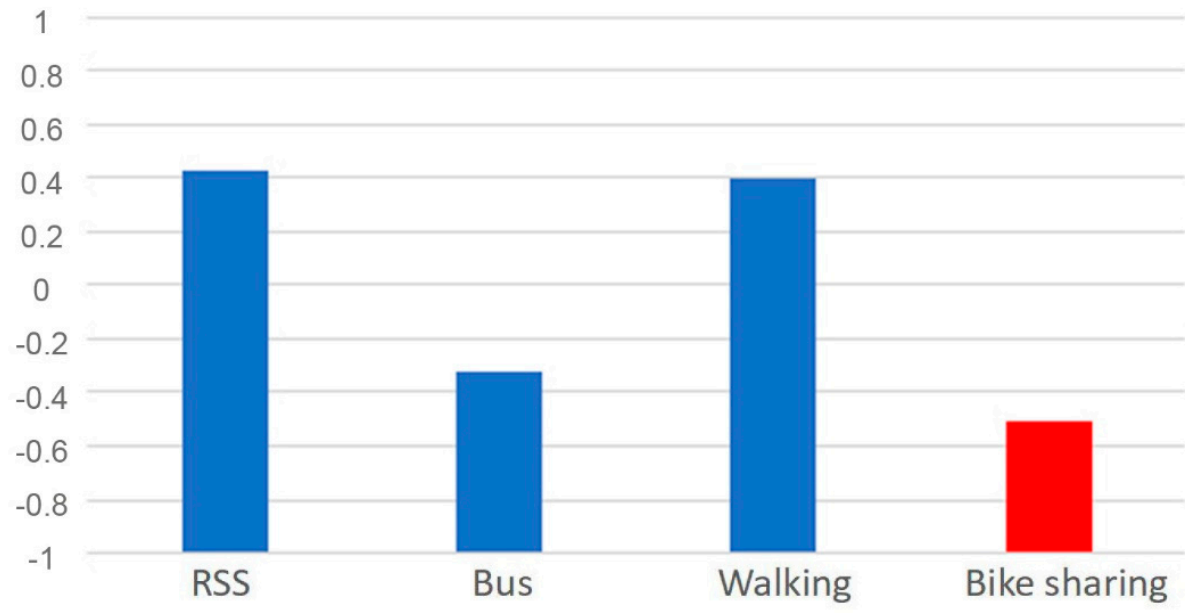

(b) Distance $=2 \mathrm{~km}$

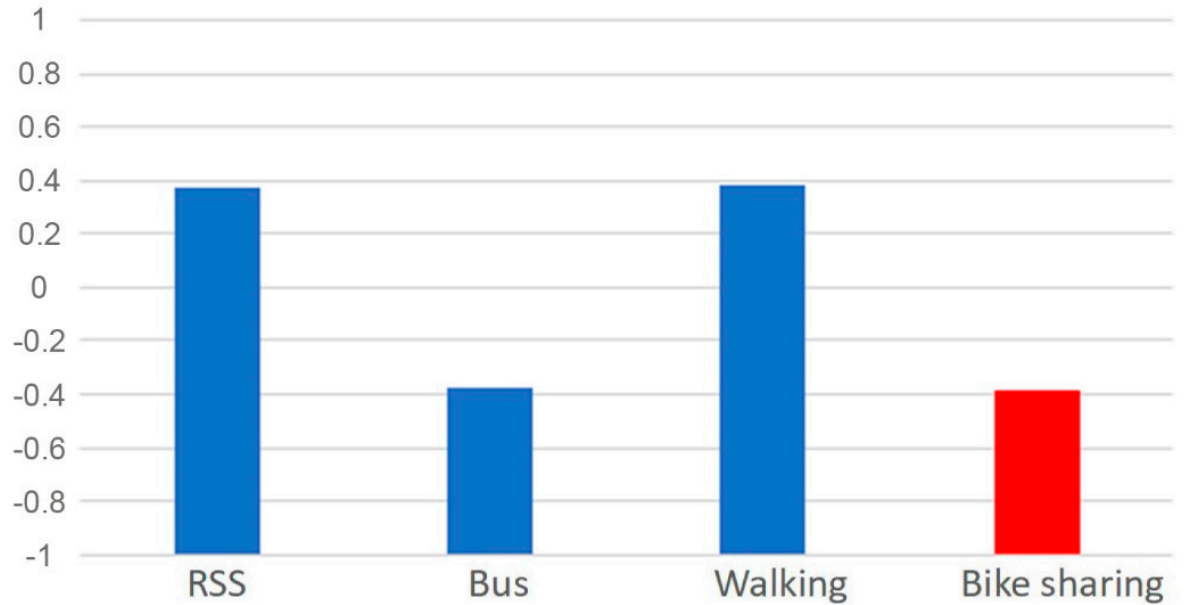

Figure 2. Mode ranking for 1 and $2 \mathrm{~km}$ trips.

Figure 3 reveals the results of the other three scenarios (travel distance $=3,4$, or $5 \mathrm{~km}$ ). As last-mile distance is relatively long, multiple modes (e.g., walking + bus) for a trip are considered. Figure 3a shows that, in the $3 \mathrm{~km}$ trip scenario, the best mode choice is still bike-sharing, closely followed by the bus. Using multiple travel modes can alleviate the disadvantages of single travel modes and further improve travel efficiency in some cases. It, however, may involve two out-of-vehicle times (e.g., one bike-searching time and one wait-for-bus time), so it does not have a high ranking.

Figure $3 \mathrm{~b}, \mathrm{c}$ show that the community bus becomes the best travel choice for the $4 \mathrm{~km}$ and $5 \mathrm{~km}$ last-mile trips. This finding agrees with expectations and is consistent with the observation in other contexts, which indicates that people prefer to use motorized mode (rather than walking and cycling) in long-range last-mile trips [37]. Travel-time differentials (mainly attributed to speed differentials) across modes become more obvious with a longer distance. With the increase of travel distance, the speed disadvantage of bike-sharing (compared to that of the bus and the RSS) gradually appears. Although the speed of the RSS is higher than the bus, the monetary cost is higher. In addition, the bus can carry more passengers, and the direct carbon emissions per passenger are fewer than the RSS. 
(a) Distance $=3 \mathrm{~km}$

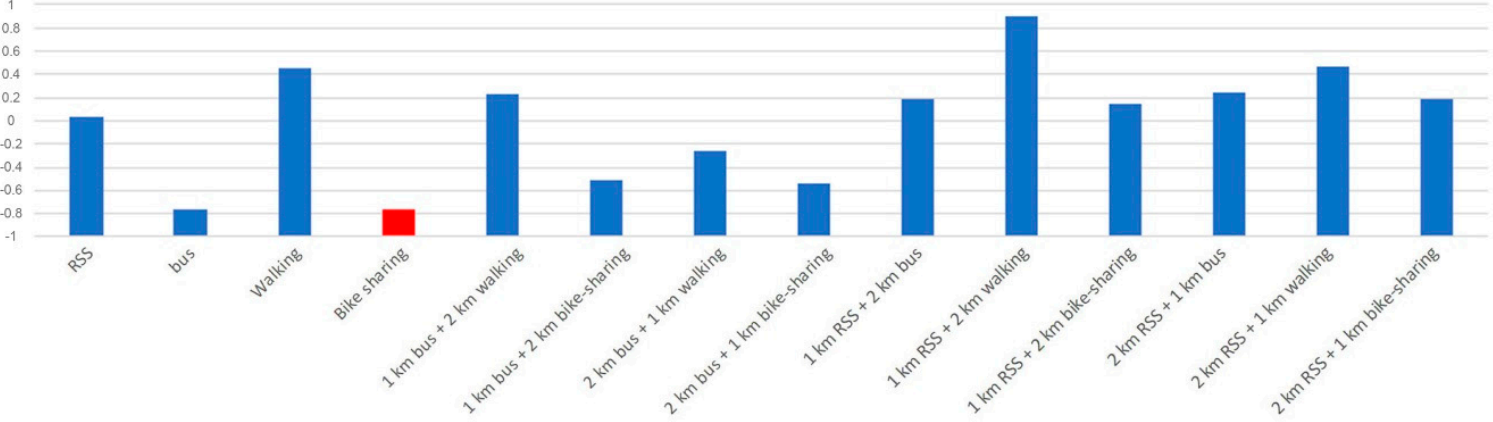

(b) Distance $=4 \mathrm{~km}$

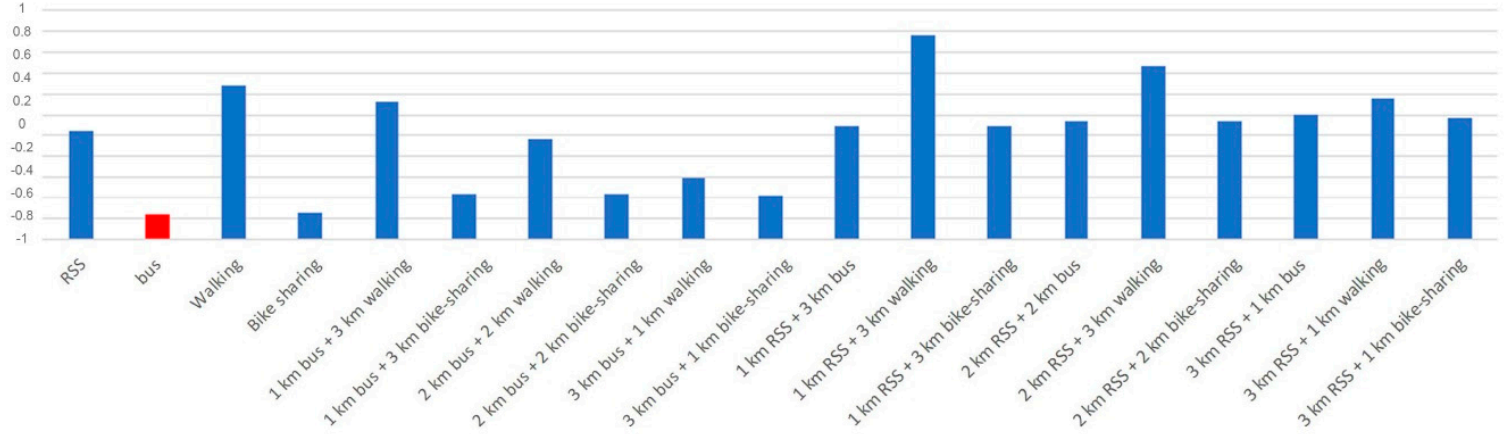

(c) Distance $=5 \mathrm{~km}$

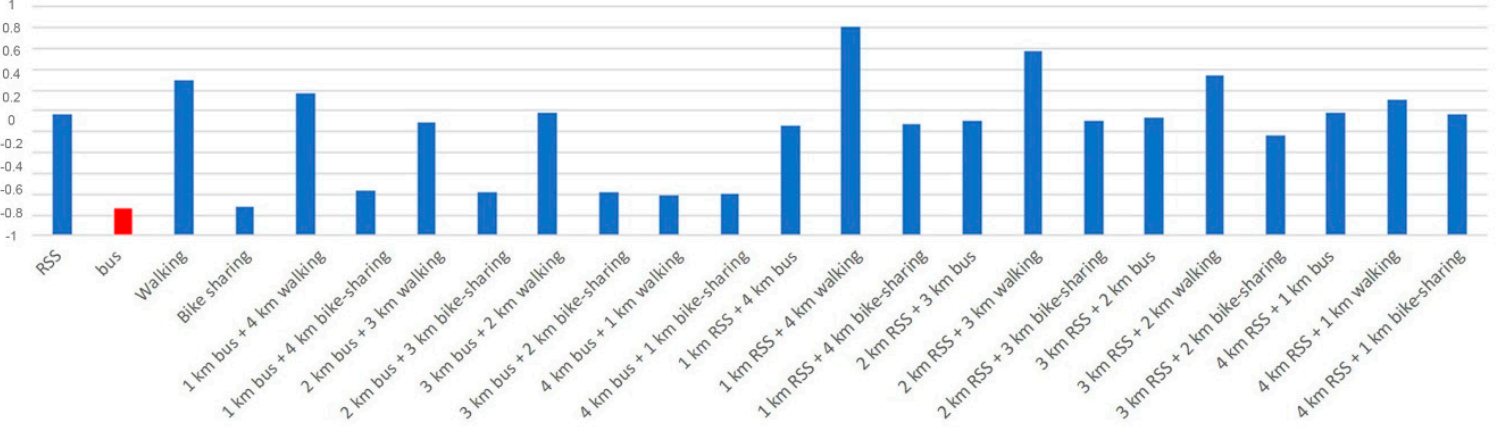

Figure 3. Mode ranking for 3, 4, and $5 \mathrm{~km}$ trips.

Although walking involves no out-of-vehicle time and monetary cost and produces no emissions, it has obvious disadvantages in terms of travel speed and travel time. This feature is more obvious with the increase of distance, as Figures 2 and 3 show.

\subsection{Discussion}

According to the results of this study, it is suggested that governments, urban transportation planners, and operators improve bike-sharing (for short last-mile trips) and the community bus service (for long last-mile trips). A few years ago, only station-based bike-sharing was available, and people must use a smart card to unlock, use, and pay for it, and the associated registration process is overly complicated. But dockless bike-sharing has gradually replaced station-based bike-sharing in numerous Chinese cities [38-41]. The implementation of smartphone payments has been the norm in today's China, substantially simplifying the previously complicated registration process. Dockless bike-sharing has the potential to effectively meet, at least a large proportion of, short-range last-mile travel demands.

Bike-sharing operators can propose measures or strategies to promote the use of bike-sharing for last-mile trips, especially those of short distance $(<3 \mathrm{~km})$. As an example, the "Call a Bike" program crafted by German Railway in Berlin aims to attract transit riders to use bike-sharing for first- or 
last-mile. The system intends to send an access code to bike-sharing users as per their request via phone calls or smartphone applications [42]. In addition, discounts are available for bike-sharing users when they combine the membership with the annual transit pass [43]. As a bonus of using bike-sharing for last-mile, transit takers can receive a reward of extra free-service time of using bike-sharing, such as $90 \mathrm{~min}$ in Hangzhou, China. However, such strategies involve at least two operators (transit and bike-sharing), so the inter-operator coordination and integration in terms of ticketing or revenue sharing are indispensable. Furthermore, in order to decrease the number of idle bikes and uplift the fluidity of bike-sharing, frequently rebalancing or adjusting bikes according to real-time demand, particularly during peak times, is necessary [44].

In addition to numerous measures or strategies proposed by operators, urban planning strategies are also significant to promote the use of bike-sharing in last-mile. Griffin and Sener [45] suggested a framework of collaborative and intermodal planning to strengthen the bike-sharing-transit connection. They addressed that planners can leverage information on existing transport systems for planning at local and regional levels when expanding a bike-sharing system. For instance, in Chicago and Austin, some additional improvements to the cycling network, such as adding protected bike lanes on existing roadways, are necessary. However, planning strategies for the integration of dockless-bike-sharing transit can be different from the traditional station-based bike-sharing-transit integration. Given that dockless shared bikes are densely distributed near transit (e.g., metro) stations and are often parked randomly [12], the key focus of planning may be the regulation of disordered parking behaviors and the improvement of parking spaces near transit stations to achieve efficient dockless bike-sharing-transit integration. Related strategies include setting the electronic fence and recommending parking areas (marked with a white rectangle on the ground).

The community bus for long-range last-mile trips (equal to or over $4 \mathrm{~km}$ ) is advocated by our results. The community bus is a type of paratransit that operates on the borderline between public and private transport in terms of cost and quality of service. It complements and serves the areas devoid of conventional mass transit, primarily serving as service-gap fillers [46,47]. However, due to the paratransit nature, it has long been ignored by traditional, formal transportation planning and policy. Extending the community bus network to cover more communities, especially those left unserved by conventional transit, is suggested. Moreover, it can be demand-responsive and may not have fixed routes and schedules, so time-varying services become possible. For example, operators can flexibly adjust the bus alignment and schedules to effectively meet the mobility needs of last-mile travelers.

In order to guide residents to choose low-carbon and environmentally friendly travel modes, introducing a "Carbon Credits" system to quantify the use of low-carbon travel methods in the form of credits is suggested $[48,49]$. For example, when residents choose to travel by bike-sharing or the bus, they can obtain some credits. When the credits are accumulated to a certain amount, rewards (e.g., bike-sharing-use discount) can be offered to promote the reduction of carbon emissions. Such an approach is of paramount importance, especially in an era with increasing awareness of environmental protection all over the world [31,50].

We should bear in mind that the discussions presented above are based on today's transport system and modes, because presently, transport modes available to city residents are still limited now in Chengdu, China. Introducing "new" transport options is, therefore, both indispensable and urgent. Luckily, a large number of novel matters that have recently or would shortly come into the transportation sector (e.g., connected and autonomous vehicles or intelligent connected vehicles and ubiquitous artificial intelligence applications) have the potentials to further satisfy the demands of travel (not necessarily limited to last-mile) and to drastically change a great many aspects in the transport system [51]. We believe that they should ignite a tremendous fascination in local and international transportation researchers alike. 


\section{Conclusions}

In general, transit offers stop-to-stop services rather than door-to-door services, and its riders need to travel to the final destination after departing from a transit hub. As such, last-mile trips become an inevitable, essential component for transit travel. The last-mile trip mode selection bears attention from policy makers and academics. Identifying the optimal mode for last-mile travel (e.g., walking and bike-sharing) can be deemed as a MADM problem, which involves the determination of weights according to some methods. However, the methods have their own specific characteristics, strengths, and drawbacks.

In this study, we propose a data-mining-based MADM for the last-mile travel-mode selection. Four last-mile travel modes, including walking, bike-sharing, community bus, and RSS in Chengdu, China, is ranked by using three sets of criteria (i.e., travel time, travel cost, and low carbon performance) and Sina Weibo data. The corresponding results demonstrate the practical application of the approach, and they are listed as follows: (1) the optimal travel mode highly varies by the distance of the "last-mile". (2) Bike-sharing serves as the optimal travel mode if the last-mile distance is shorter than $3 \mathrm{~km}$. (3) The community bus becomes the optimal travel mode if the distance ranges from 4 to $5 \mathrm{~km}$. It is expected that this study offers an evidence-based approach to guiding residents to choose the reasonable last-mile travel mode and provides insights into developing a sustainable urban transport system.

Currently, new data or big data are ubiquitous, and how to effectively use them for research purposes is important. As this study shows, using the data-mining technique has the potential to supplement, augment, and advance traditional MADM weight determination methods, but certainly, it cannot fully replace them. This study puts forward an innovative approach of using word frequency as the weight. However, it is the only way of weighting, and there are many possibilities of using big data for weight determination. This can be extensively explored in future research.

There are some limitations that highly deserve future research. First, we took an overly simplistic approach to determine the weights, namely, carefully selecting several keywords for each criterion. However, due to the subjectivity and non-exhaustion of this approach, we may miss some potentially important keywords. As such, more sophisticated methods, such as semantic recognition, can be tested in upcoming studies. Second, the travel time in this study is estimated by dividing the travel distance by the whole-day average travel time of each mode. However, travel times for the same origin-destination pair are vastly different under different conditions (e.g., peak (congested) hours and off-peak (free-flow) hours) [52]. Therefore, determining travel times (a measure of transportation accessibility) and corresponding optimal last-mile travel modes in different times of day (e.g., evening peak hours and noon off-peak hours) merit further research.

Author Contributions: Conceptualization, R.Z., L.Y., X.L., Y.Z., and X.R.; methodology, R.Z.; software, X.L., Y.Z., and X.R.; validation, L.Y., Y.G., and Y.L.; formal analysis, X.L., Y.Z., and X.R.; writing-original draft preparation, L.Y.; writing - review and editing, R.Z., Y.G., and Y.L.; supervision, R.Z.; project administration, R.Z.; and funding acquisition, R.Z.

Funding: This study was sponsored by the National Natural Science Foundation of China (No.41571520), the Sichuan Provincial Key Technology Support (No. 2019JDJQ0020), the Sichuan Province Circular Economy Research Center Fund (No. XHJJ-1802), and the Research Grants Council of the Hong Kong Special Administrative Region, China (No. CityU11666716).

Acknowledgments: The authors are grateful to the three reviewers for their helpful comments.

Conflicts of Interest: The authors declare no conflict of interest.

\section{References}

1. Cervero, R.; Kockelman, K. Travel demand and the 3Ds: Density, diversity, and design. Transp. Res. D Transp. Environ. 1997, 2, 199-219. [CrossRef] 
2. Yang, L.; Zhou, J.; Shyr, O.F.; Huo, D.D. Does bus accessibility affect property prices? Cities 2019, 84, 56-65. [CrossRef]

3. Bauman, A.E.; Reis, R.S.; Sallis, J.F.; Wells, J.C.; Loos, R.J.; Martin, B.W. Correlates of physical activity: Why are some people physically active and others not? Lancet 2012, 380, 258-271. [CrossRef]

4. Yang, L.; Wang, X.; Sun, G.; Li, Y. Modeling the perception of walking environmental quality in a traffic-free tourist destination. J. Travel Tour. Mark. 2019, 1-16. [CrossRef]

5. Heath, G.W.; Parra, D.C.; Sarmiento, O.L.; Andersen, L.B.; Owen, N.; Goenka, S.; Montes, F.; Brownson, R.C. Evidence-based intervention in physical activity: Lessons from around the world. Lancet 2012, 380, $272-281$. [CrossRef]

6. Cheng, L.; Chen, X.; Yang, S.; Cao, Z.; De Vos, J.; Witlox, F. Active travel for active ageing in China: The role of built environment. J. Transp. Geogr. 2019, 76, 142-152. [CrossRef]

7. Xu, W.A.; Yang, L. Evaluating the urban land use plan with transit accessibility. Sustain. Cities Soc. 2019, 45, 474-485. [CrossRef]

8. Xu, W.A.; Zhou, J.; Yang, L.; Li, L. The implications of high-speed rail for Chinese cities: Connectivity and accessibility. Transp. Res. Part A Policy Pract. 2018, 116, 308-326.

9. Lund, H. Pedestrian environments and sense of community. J. Plan. Educ. Res. 2002, 21, 301-312. [CrossRef]

10. Leyden, K.M. Social capital and the built environment: The importance of walkable neighborhoods. Am. J. Public Health 2003, 93, 1546-1551. [CrossRef]

11. Munoz-Raskin, R. Walking accessibility to bus rapid transit: Does it affect property values? The case of Bogotá, Colombia. Transp. Policy 2010, 17, 72-84. [CrossRef]

12. Zhao, D.; Wang, D. The research of tripartite collaborative governance on disorderly parking of shared bicycles based on the theory of planned behavior and motivation theories-A Case of Beijing, China. Sustainability 2019, 11, 5431. [CrossRef]

13. DeMaio, P. Bike-sharing: History, impacts, models of provision, and future. J. Public. Trans. 2009, 12, 41-56. [CrossRef]

14. Velasquez, M.; Hester, P.T. An analysis of multi-criteria decision making methods. Int. J. Oper. Res. 2013, 10, 56-66.

15. Saaty, T.L. What is the analytic hierarchy process? In Mathematical Models for Decision Support; Springer: Berlin/Heidelberg, Germany, 1988; pp. 109-121.

16. Emrouznejad, A.; Marra, M. The state of the art development of AHP (1979-2017): A literature review with a social network analysis. Int. J. Prod. Res. 2017, 55, 6653-6675. [CrossRef]

17. Zhao, R.; Su, H.; Chen, X.; Yu, Y. Commercially available materials selection in sustainable design: An integrated multi-attribute decision making approach. Sustainability 2016, 8, 79. [CrossRef]

18. Mulliner, E.; Malys, N.; Maliene, V. Comparative analysis of MCDM methods for the assessment of sustainable housing affordability. Omega 2016, 59, 146-156. [CrossRef]

19. Salonen, M.; Broberg, A.; Kyttä, M.; Toivonen, T. Do suburban residents prefer the fastest or low-carbon travel modes? Combining public participation GIS and multimodal travel time analysis for daily mobility research. Appl. Geogr. 2014, 53, 438-448. [CrossRef]

20. Ortuzar, J.D.D. Nested logit models for mixed-mode travel in urban corridors. Transp. Res. Part A Policy Pract. 1983, 17, 283-299. [CrossRef]

21. Stern, S. A disaggregate discrete choice model of transportation demand by elderly and disabled people in rural Virginia. Transp. Res. Part A Policy Pract. 1993, 27, 315-327. [CrossRef]

22. Schmöcker, J.D.; Quddus, M.A.; Noland, R.B.; Bell, M.G. Mode choice of older and disabled people: A case study of shopping trips in London. J. Transp. Geogr. 2008, 16, 257-267. [CrossRef]

23. Wang, Q.; Feng, X.S.; Liu, Y.; Wang, X.Y.; Zhang, H.M.Z. Urban Travel Mode Split Optimization Based on Travel Costs. In 9th International Conference on Traffic and Transportation Studies; Mao, B., Tian, Z., Gao, Z., Huang, H., Feng, X., Eds.; Elsevier Science Bv: Amsterdam, The Netherlands, 2014; Volume 138, pp. 706-714.

24. Schwanen, T.; Dijst, M.; Dieleman, F.M. Leisure trips of senior citizens: Determinants of modal choice. Tijdschr. Econ. Soc. Geogr. 2001, 92, 347-360. [CrossRef]

25. Su, F.; Schmöcker, J.D.; Bell, M.G. Mode choice of older people before and after shopping. J. Transp. Land Use 2009, 2, 29-46. [CrossRef]

26. Tilahun, N.; Thakuriah, P.V.; Li, M.; Keita, Y. Transit use and the work commute: Analyzing the role of last mile issues. J. Transp. Geogr. 2016, 54, 359-368. [CrossRef] 
27. Moniruzzaman, M.; Páez, A. Accessibility to transit, by transit, and mode share: Application of a logistic model with spatial filters. J. Transp. Geogr. 2012, 24, 198-205. [CrossRef]

28. Jenelius, E. Public transport experienced service reliability: Integrating travel time and travel conditions. Transp. Res. Part A Policy Pract. 2018, 117, 275-291. [CrossRef]

29. Yang, Y.; Wang, C.; Liu, W.; Zhou, P. Understanding the determinants of travel mode choice of residents and its carbon mitigation potential. Energ. Policy 2018, 115, 486-493. [CrossRef]

30. Koopmans, C.; Groot, W.; Warffemius, P.; Annema, J.A.; Hoogendoorn-Lanser, S. Measuring generalised transport costs as an indicator of accessibility changes over time. Transp. Policy 2013, 29, 154-159. [CrossRef]

31. Balsa-Barreiro, J.; Li, Y.; Morales, A. Globalization and the shifting centers of gravity of world's human dynamics: Implications for sustainability. J. Clean. Prod. 2019, 239, 117923. [CrossRef]

32. He, D.; Liu, H.; He, K.; Meng, F.; Jiang, Y.; Wang, M.; Zhou, J.; Calthorpe, P.; Guo, J.; Yao, Z. Energy use of, and $\mathrm{CO} 2$ emissions from China's urban passenger transportation sector-Carbon mitigation scenarios upon the transportation mode choices. Transp. Res. Part A Policy Pract. 2013, 53, 53-67. [CrossRef]

33. Cao, X.; Yang, W. Examining the effects of the built environment and residential self-selection on commuting trips and the related $\mathrm{CO}_{2}$ emissions: An empirical study in Guangzhou, China. Transp. Res. D Transp. Environ. 2017, 52, 480-494. [CrossRef]

34. Neves, A.; Brand, C. Assessing the potential for carbon emissions savings from replacing short car trips with walking and cycling using a mixed GPS-travel diary approach. Transp. Res. Part A Policy Pract. 2019, 123, 130-146. [CrossRef]

35. Wu, X.; Lu, Y.; Lin, Y.; Yang, Y. Measuring the destination accessibility of cycling transfer trips in metro station areas: A big data approach. Int. J. Environ. Res. Public Health 2019, 16, 2641. [CrossRef] [PubMed]

36. Ho, W.; Xu, X.; Dey, P.K. Multi-criteria decision making approaches for supplier evaluation and selection: A literature review. Eur. J. Oper. Res. 2010, 202, 16-24. [CrossRef]

37. Meng, M.; Koh, P.P.; Wong, Y.D. Influence of socio-demography and operating streetscape on last-mile mode choice. J. Public Trans. 2016, 19, 38-54. [CrossRef]

38. Ji, Y.; Ma, X.; Yang, M.; Jin, Y.; Gao, L. Exploring spatially varying influences on metro-bikeshare transfer: A geographically weighted Poisson regression approach. Sustainability 2018, 10, 1526. [CrossRef]

39. Jia, L.; Liu, X.; Liu, Y. Impact of different stakeholders of bike-sharing industry on users' intention of civilized use of bike-sharing. Sustainability 2018, 10, 1437. [CrossRef]

40. Lin, J.J.; Zhao, P.; Takada, K.; Li, S.; Yai, T.; Chen, C.H. Built environment and public bike usage for metro access: A comparison of neighborhoods in Beijing, Taipei, and Tokyo. Transp. Res. D Transp. Environ. 2018, 63, 209-221. [CrossRef]

41. Ma, X.; Ji, Y.; Jin, Y.; Wang, J.; He, M. Modeling the factors influencing the activity spaces of bikeshare around metro stations: A spatial regression model. Sustainability 2018, 10, 3949. [CrossRef]

42. Paul, F.; Bogenberger, K. Evaluation-method for a station based urban-pedelec sharing system. Transp. Res. Proc. 2014, 4, 482-493. [CrossRef]

43. Bachand-Marleau, J.; Lee, B.H.; El-Geneidy, A.M. Better understanding of factors influencing likelihood of using shared bicycle systems and frequency of use. Transp. Res. Rec. 2012, 2314, 66-71. [CrossRef]

44. Faghih-Imani, A.; Eluru, N. Determining the role of bicycle sharing system infrastructure installation decision on usage: Case study of montreal BIXI system. Transp. Res. Part A Policy Pract. 2016, 94, 685-698. [CrossRef]

45. Griffin, G.P.; Sener, I.N. Planning for bike share connectivity to rail transit. J. Public Trans. 2016, 19, 1-22. [CrossRef] [PubMed]

46. Cervero, R.; Golub, A. Informal transport: A global perspective. Transp. Policy 2007, 14, 445-457. [CrossRef]

47. Rimmer, P. Paratransit: A commentary. Environ. Plan. A 1980, 12, 937-944. [CrossRef]

48. Zhao, R.; Min, N.; Geng, Y.; He, Y. Allocation of carbon emissions among industries/sectors: An emissions intensity reduction constrained approach. J. Clean. Prod. 2017, 142, 3083-3094. [CrossRef]

49. Zhao, R.; Geng, Y.; Liu, Y.; Tao, X.; Xue, B. Consumers' perception, purchase intention, and willingness to pay for carbon-labeled products: A case study of Chengdu in China. J. Clean. Prod. 2018, 171, 1664-1671. [CrossRef]

50. Huang, W.; Shuai, B.; Sun, Y.; Wang, Y.; Antwi, E. Using entropy-TOPSIS method to evaluate urban rail transit system operation performance: The China case. Transp. Res. Part A Policy Pract. 2018, 111, 292-303. [CrossRef] 
51. Yap, M.D.; Correia, G.; Van Arem, B. Preferences of travellers for using automated vehicles as last mile public transport of multimodal train trips. Transp. Res. Part A Policy Pract. 2016, 94, 1-16. [CrossRef]

52. Fransen, K.; Neutens, T.; Farber, S.; De Maeyer, P.; Deruyter, G.; Witlox, F. Identifying public transport gaps using time-dependent accessibility levels. J. Transp. Geogr. 2015, 48, 176-187. [CrossRef]

(C) 2019 by the authors. Licensee MDPI, Basel, Switzerland. This article is an open access article distributed under the terms and conditions of the Creative Commons Attribution (CC BY) license (http://creativecommons.org/licenses/by/4.0/). 